\title{
The chains of education, experience, and culture
}

\author{
David Metcalfe
}

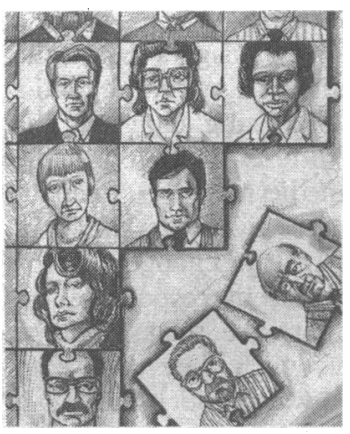

This is the last in a series of articles dealing with aspects of managing change in general practice.

Department of General Practice, University of Manchester, Manchester M14 5NP

David Metcalfe, professor

BMF 1992;305:33-4
The striking thing about the series of articles on managing change in primary care is that while it will be seen as worthy but not saying anything new by many general practitioners, there will be an equal number to whom it will be revelatory, and possibly another group who will either reject the ideas or avoid reading the articles altogether. The "limiting condition" of general practice is its heterogeneity, and that heterogeneity is its Achilles' heel as far as managers and politicians are concerned.

In fact there are two components to this heterogeneity, one more defensible than the other. As general practitioners are, or try to be, responsive to their patients' needs practice activity and style will be different in different places-for example, in the BMW lined "villages" of the home counties compared with the shattered manufacturing centres of the north east. That sort of heterogeneity is right and proper. That which comes from self indulgence and intellectual sloth is not. Why is there such variation?

\section{A triangle of forces}

The variations in values and attitudes, and therefore behaviour, among general practitioners represent the interaction of three influences on them as people (the fact that they are people seems often to be overlooked by those within and outside the profession). These are education, experience, and culture, which should be seen as a triangle of forces. Thus the same experience of change will provoke different reactions depending on the individual's educational or cultural background. Similarly, the same education given to people of differing culture will result in differing attitudes to change. Why, for instance, does the experience of working under an autocratic and exploitative senior partner lead some general practitioners rigorously to avoid following suit, while others can't wait to assume the senior partner's mantle?

The shortcomings of medical education and training are all too well known. It singularly fails to teach the use of clinical logic to manage uncertainty and that general practice, dealing with initially small variations from normal health without instant recourse to technological investigation, centres on the management of uncertainty, and therefore leaves the alumni with a load of anxiety.

Experience isn't history, it's biography. Of the myriad things that happen to us or which we see happen to others only those which are "internalised"that is, connected up with our other observations and values-constitute experience. Essentially, therefore, experience as a predictor of response to change or suggested change is to do with feelings, and may not be strictly "rational" or "objective."

\section{The culture of power}

But education and experience are not superimposed on a blank sheet. They happen to people who belong to, or come from, a given background, characterised by its values and beliefs: a culture. These values and beliefs are absorbed from our earliest years and are strongly influenced by the community in which we
- Medical education fails to teach the use of clinical logic to manage uncertainty

- Experience as a predictor of response to change is to do with feelings and not strictly objective

- As well as social class and ethnicity doctors' beliefs are shaped by their role models throughout their training, and these will influence their response to change

grow up, and therefore by factors such as ethnicity, social class, and local ways of looking at things (for instance, the difference in views between north and south, whether Scandinavian compared with Italian, or Cumbrian compared with Kentish).

Such absorption isn't limited to childhood, and values and beliefs continue to be inculcated as we clamber up the educational ladder. As we do so, the power of precept is displaced by that of example, and role models, negative as well as positive, become strong influences on attitudes and values. The power exercised by senior clinicians and the way they exercise power is perhaps central to their influence as models. The most important aspect of culture with regard to change in general practice is power.

The traditional British system of teaching values, inculcated by the public schools and the forces for which they were preparing people, was that power and privilege had to be earned by taking responsibility (hence the prefect, the junior officer). This method may always have been for a minority of people, and certainly is now, when it seems that power is seen as a desirable end in itself, and responsibility an unfortunate and hopefully avoidable encumbrance. But the practice of medicine starts with responsibility, and to discharge that responsibility you often have to exert power. (In the Larrinaga operating theatre of the old Liverpool Royal Infirmary was a quote from Hippocrates along the lines of "It is the duty of the surgeon to make his assistants and the patient cooperate with him"). N Unfortunately in the traditional British culture power, $>$ like enthusiasm and cleverness, is deeply suspect, and therefore disguised, so that the exercising of it is often covert, idiosyncratic, and arbitrary.

\section{The value of respect}

Over and over again in this series of articles the question of relationships within hierarchies, whether between partners or between principals and other members of staff has come up but seldom been addressed in cultural terms, and, in particular in terms of the culture of power. In any organisation who has power over whom, and what sort of power, and how it is exerted, are crucial factors in the way the organisation \& works. Does seniority confer power; if it does, why, and what sort of power; and is this generally accepted ô within the practice? These things are unlikely to have $\rightleftharpoons$ been dealt with explicitly. Are staff colleagues, subordinates, or servants (in reality if not in name)? Useful evidence is the use of first names, nicknames, or titles.

The abuse of power can and does obstruct growth 


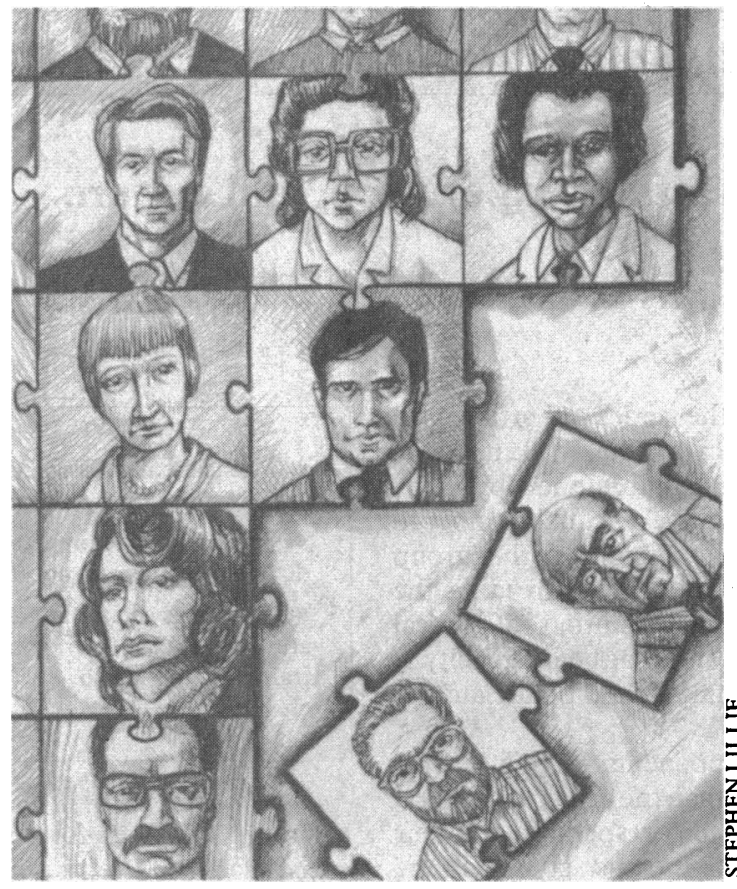

and desirable change, but growth and change can be achieved only by the proper exercising of power. Management training, good chairmanship, well organised meetings, force field analysis, Belbin inventories, and all the rest of the important tools discussed in this series will be of little avail if the existence of power is dishonestly concealed, if it is arrogated rather than awarded (sapiential leadership), or if it is used capriciously. It has to be faced that organisations, including practices, are not democracies: power is not evenly distributed (any more than rewards), and the pretence that it is can lead to disillusionment and resentment when the chips are down.

What must be evenly distributed is respect: everybody who does his or her job properly is entitled to the wholehearted respect of every other member of the practice. A person who knows that he or she has the respect of colleagues has the personal space to cope with change. Someone who feels undervalued has to rely on self esteem, which is tied up with day to day activities. If the tea lady feels she is the only person who realises how much she is needed and how carefully she makes and presents the vital fluid, she is unlikely to welcome the introduction of a vending machine so as to free her to take on other responsibilities.

\section{Differences in social class}

Unfortunately another characteristic of British culture is its subtle and pervasive class consciousness. Not only power, but personal space and the right to respect vary with status on the many runged ladder of perceived class. But just as power is too uncomfortable a concept in this culture to be dealt with openly and honestly so is class consciousness. Other cultures from which many general practitioners come, have wider class differences and different ways of handling them. As a result relationships within hierarchies are likely to be coloured by subliminal feelings about class and therefore worth.

To understand the interaction between education and culture as predictors of reaction to and ability to cope with or manage change we have only to think of students' observations of life on the wards and the behaviour of their role models there. Students from middle class backgrounds are likely to accept the exercising of power and perfunctory courtesy towards others exhibited by some consultants as desirable features in their role models, while those from more disadvantaged and politically angry backgrounds may draw exactly opposite conclusions. Both sets of attitudes will colour their subsequent behaviour.

\section{Heterogeneities of general practice}

Politicians, civil servants, and managers regard the heterogeneity of general practice as a bad thing, and a challenge to their skills in imposing change. The important thing is for them to differentiate between the heterogeneity that stems from the negative effects of the education, experience, and culture triangle of forces, which is a legitimate target for change towards homogeneity, and that which represents responsiveness to local needs and wants. Furthermore, they should be careful about the criteria by which they choose to define the pattern of practice towards which they wish to move. At first sight these may centre on the features of highly organised practices with computerised systems and training facilities, in purpose built premises with regular team meetings, etc, and decry the single handed practitioner in shabby surroundings. This range of general practitioners might, however, conceal another-from authoritarian doctors who impose the college model in which everyone must toe the line, including patients, to those who provide responsive and sensitive care, who have reacted against regimentation and stayed in the urban jungle because that's where his or her patients felt comfortable.

General practitioners are highly defensive: they still believe that general practice is seen as second class medicine; NHS high brass often talk about it as if it were outside the NHS. At the interface between the NHS and people's health care needs and between primary and secondary care general practice has had no choice but to accommodate to enormous change in needs, the way they are presented, and the technology with which they are met. "Conservatism" in some practices may represent a desperate attempt to hang on to something in a maelstrom of change. (McMillan and Pringle in their article on practice managers quote from Whitehead: "The art of progress is to preserve order amid change, and preserve change amid order.")

\section{Conclusion}

If heterogeneity in practice performance and, indeed, in response to these articles reflects different resultant behaviours from the interaction between culture, education, and experience, then there is little to be gained by prescribing ways of coping with change, or initiating it, as if they were applicable to all practices and all practitioners. General practitioners and their colleagues will cope with change better if they start by reviewing, honestly and openly, the distribution of power and respect within their partnerships and practices. This is always difficult and often painful: it takes time and is a very private activity. To try to impose it from outside would be counterproductive. Family health services authorities must take this on board and try to work "with the grain."

This series has been edited by Dr Mike Pringle. 